\title{
Stroke pioneer changed prevention, treatment
}

Cite as: CMAJ 2017 October 2;189:E1244-5. doi: 10.1503/cmaj.1095452

Posted on cmajnews.com on Sept. 12, 2017.

D r. Antoine Hakim received the prestigious 2017 Canada Gairdner Wightman Award for his outstanding contribution to stroke research and leadership in championing the prevention and treatment of stroke in Canada. Hakim's work to improve the understanding of the mechanisms underlying stroke, followed by establishment of the Canadian Stroke Network and the implementation of a national strategy for stroke prevention and treatment, has shifted the paradigm of the disease. Within the first five years of the implementation of the national strategy, referrals to stroke prevention clinics increased by $34 \%$ and hospital admissions for stroke in Ontario decreased $11 \%$.

Now, most people have the knowledge they need to take immediate action once they recognize the signs and symptoms of a stroke. Consequently, more patients are going home after stroke and leading normal lives. Hakim is emeritus professor of neurology at the University of Ottawa and senior neurologist at The Ottawa Hospital. This is an edited version of a recent interview with him.

You began your career as an engineer, but decided to pursue medicine and research. Why did you switch directions?

"I had an engineering kind of mind: you see a problem, you want to solve it. As a chemical engineer, I worked in the Alberta tar sands at the time when we began exploring ways to extract oil. That's a challenge I thought was worthwhile. I knew this was going to result in an industry for Canada, but not necessarily something that would help the indi-

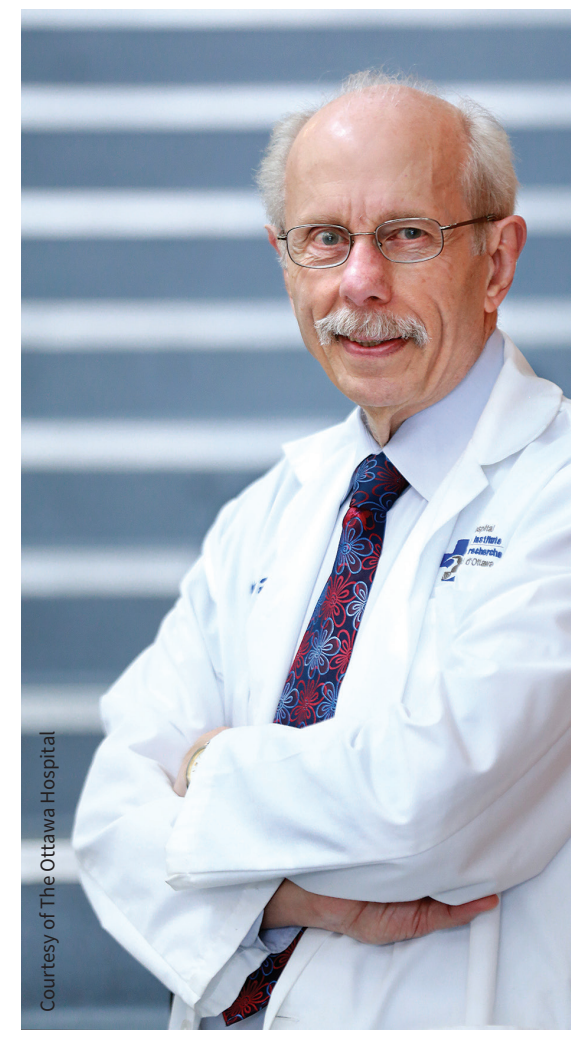

Dr. Antoine Hakim's research changed the protocol for stroke.

vidual. So I became disenchanted with that career choice. It wasn't like I woke up one morning and decided I wanted to be a doctor. It was a gradual process. I went from chemical engineering to teaching high school students in Montreal while figuring my next move, to pursuing a doctoral degree in biomedical engineering as I still wanted to be an engineer. During my doctoral studies, I had common lectures with medical students and discovered that I was interested in medicine. I think that was evident to my teachers, as well, who encouraged me to apply to medical school...and the rest is history!"

\section{What sparked your interest in} stroke?

"I became interested in the brain and its functions during my doctoral studies. In fact, some of the first papers I wrote [involved] applying mathematical principles to quantitating numerous pathways in the brain.... Then, I picked neurology for my residency.... It was awful to see patients that one day would be fine and the following day would be totally handicapped for the rest of their lives with a stroke. We studied the risk factors, but we had no solution once it happened. Thus, stroke, as this sudden catastrophic event that handicapped people and their families, motivated me to expand my knowledge about it."

\section{Did you have an aha moment?}

"There were multiple aha moments! One was discovering that the penumbra existed in the human brain, and not only monkey or rat brains. We confirmed, in humans, the concepts from the laboratory that when a stroke occurs, even though it results in a deficit, this deficit to some extent is reversible for a number of hours."

\section{You were instrumental in the} development of the Canadian Stroke Network (CSN). Can you elaborate upon your role?

"The CSN meant bringing together the public, patients, basic scientists, paramedics and clinicians towards a common goal of bringing the patient to the emergency room to receive the drug in a short span of time. This was a massive job and we partnered with the Heart and Stroke Foundation, approached politicians and hospital directors. Through this role I learned not to underestimate anybody's 
drive to contribute to society. That's something I think we do better in Canada. We're not so driven by "what's in it for me?", but we transcend that to think about what's in it for society. So, the CSN succeeded."

What would you consider the most important contribution of the CSN? "It illustrated that individuals across the spectrum collaborate towards a common goal once they're convinced they have a role to play and the outcome is worth it. In fact, the Canadian health budget saved billions of dollars from the CSN activities."

\section{Can you elaborate on your} interaction with politicians?

"Politicians work hard and want to do the right thing, but quickly learn that if they don't demonstrate success within a short time span, they may not get re-elected. So your challenge as a researcher is to speak to them in a way which is interesting to them. Moreover, it's important to have a vision you can present."

\section{What are you working on now?}

"Recently, I've published a book, Save Your Mind: 7 Rules to Avoid Dementia. My interest in dementia arose from my work on stroke. We learned that for every one of the evident strokes, there are ten occult ones. This is how common it is to injure the brain a small bit at a time in individuals with untreated vascular risk factors, ultimately resulting in cognitive challenges. Using dementia as a driver, the book focuses on protecting the brain while aging. It's based on science and is intended for the public."
What's your advice for young scientists?

1. Follow your heart, not your brain.

2. Don't be afraid to change course. The world has changed for young people. It means you have to be open-minded and willing to explore new paths!

Editor's note:To commemorate the recent 30th anniversary of the Canadian Student Health Research Forum (CSHRF), four recipients of Gairdner awards gave public lectures highlighting their achievements. CSHRF participants were selected to interview these laureates. Michelle Chakraborti is a PhD candidate in the experimental medicine graduate program at the University of British Columbia.

Michelle Chakraborti, Vancouver, BC 